Article

\title{
Diversity in Western Countries: Journalism Culture, Migration Integration Policy and Public Opinion
}

\author{
Stefan Mertens ${ }^{1, *}$, Oivier Standaert ${ }^{2}$, Leen $\mathrm{d}^{\prime}$ Haenens ${ }^{1}$ and Rozane de Cock ${ }^{1}$ \\ ${ }^{1}$ Institute for Media Studies, KU Leuven, 3000 Leuven, Belgium, E-Mails: stefan.mertens@kuleuven.be (S.M.), \\ leen.dhaenens@kuleuven.be (L.d'H.),rozane.decock@kuleuven.be (R.d.C.) \\ ${ }^{2}$ Louvain School of Journalism, Université Catholique de Louvain, 1348 Louvain-La-Neuve, Belgium, \\ E-Mail: olivier.standaert@uclouvain.be \\ * Corresponding author
}

Submitted: 15 June 2018 | Accepted: 8 January 2019 | Published: 5 February 2019

\begin{abstract}
Earlier research has shown that public opinion and policy lines on the topic of immigrant integration are interrelated. This article investigates a sample of 24 countries for which data are available in the Migrant Integration Policy Index (MIPEX), the World Values Survey (WVS), as well as in the Worlds of Journalism Study (WJS). To our knowledge, this is the first time that these data are connected to one another to study journalists' views on their role to promote tolerance and cultural diversity in societies with diverging immigration policies. The WJS presents an analysis of the role conceptions of professional journalists throughout the world, including a variable measuring the extent to which journalists conceive promoting tolerance and cultural diversity as one of their tasks. Our findings show that journalists (as measured in the WJS) mostly tend to promote tolerance and cultural diversity in countries with more restrictive immigration policies (measured by MIPEX) and less emancipative values (measured by the WVS) Promoting tolerance and cultural diversity is associated with a so-called interventionist approach in journalism culture. Furthermore, we used cluster analyses to attribute the countries under study to meaningful, separate groups. More precisely, we discriminate four clusters of the press among the 24 countries under investigation.
\end{abstract}

\section{Keywords}

cultural diversity; immigration; integration policy; journalism culture; public opinion; tolerance

\section{Issue}

This article is part of the issue "Communicating on/with Minorities", edited Leen d'Haenens and Willem Joris (KU Leuven, Belgium).

(C) 2019 by the authors; licensee Cogitatio (Lisbon, Portugal). This article is licensed under a Creative Commons Attribution 4.0 International License (CC BY).

\section{Cultural Values, Migrant Integration Policy, and Journalistic Role Perceptions}

For several years now, immigration has steered the policy debate in Europe and it continues doing so as new urgent matters keep on setting the agenda. Integration of immigrants and immigration as a whole is a major political issue, not only in the realm of policy, but also in those of public opinion and journalism (e.g., Watson \& Riffe, 2013). A country's cultural values can stimulate or reject immigration (Leong \& Ward, 2006). This article explores the interrelationships between data on policy, public opinion and journalistic cultures in an effort to integrate databases that were hitherto only studied separately, and we do so with an emphasis on journalistic cultures. The databases used are the Migrant Integration Policy Index (MIPEX), the World Values Survey (WVS), and the Worlds of Journalism Study (WJS).

The MIPEX classification is in fact a normative evaluation of countries whereby experts attribute scores between 0 and 100 to the list of countries, assuming at least implicitly that 'less' developed policy contexts should be 
adjusted based on the better-developed migration policies of the 'more' developed countries. 'Policy' does not operate in a cultural vacuum, so it comes as no surprise that researchers have sought and found links between the public opinion of nation states on the one hand and the latter's migration and integration policies on the other (Callens, 2015; Hooghe \& De Vroome, 2015; Schroyens, Meuleman, \& Galle, 2015). The aforementioned researchers have weighed the importance of two conflicting hypotheses. The first hypothesis states that liberal immigration policies foster competition, and hence public attitudes that oppose increased immigration. The second hypothesis that was already vindicated in research prior to ours stresses a positive correlation between a more welcoming public opinion and policies in migrant-friendly countries.

Welzel (2013)-a key specialist of the WVSdeveloped a theory of human development according to which social-economic development, emancipative cultural change, and democratization constitute a coherent entity of social progress. The author classifies countries according to their cultural values and the extent to which opportunities for emancipative values are on offer.

Communication scientists (see, e.g., Vliegenthart, 2015) have stressed the importance of a third sphere alongside cultural attitudes and policy orientations, where political issues get constructed: the media sphere. There are important agenda interactions between political actors, the general public, and the media. McCombs (2011, p. 1) argued that: "The power of the news media to set a nation's agenda, to focus public attention on a few key public issues, is an immense and welldocumented influence". Nevertheless, the impact of the media on the public is currently assessed as important, but not as unilaterally and predominantly as has been suggested by early communication scholars.

When it comes to the influence of the media on politics, most of the relevant literature confirms the existence of media effects on the political agenda (Walgrave \& Van Aelst, 2016), although contingencydepending on specific circumstances-has also been observed. Agenda's and values have been shown to be interrelated (Valenzuela, 2011). The emancipative values in national public opinion cultures and political cultures may very well go together with similar journalistic values. Investigating the extent to which this holds true is the goal of our study.

Although comparative communication research offers several merits such as revealing patterns and problems left unnoticed in a specific socio-cultural and geographical milieu, or widening the scope beyond the familiar contours when drawing attention to macro-societal developments, until recently relatively little communication research has engaged in comparative media analysis. As a result, and notwithstanding noteworthy examples, media and communication scholarship continues to remain fragmented and often nationally, geographically or case-bound (Puppis \& d'Haenens, 2012; Sarikakis,
2008). Yet, in the last two decades, more scholars are purposefully taking a comparative angle (Hanitzsch, 2008; Hanitzsch \& Altmeppen, 2007). The demand for crosscountry comparison is even bigger in a field that is expected to deliver evidence and ideas instrumental to media policy-makers, who can learn from experiences and good practices abroad.

One of the earlier attempts of cross-national media research that developed a typology of media systems was the "Four Theories of The Press" model by Siebert, Peterson and Schramm (1956). This classic work of reference identified the libertarian theory, the authoritarian theory, the communist theory and the social responsibility theory. Although the research in this chapter is mainly devoted to Europe, we paraphrase the four theories of the press in our development of different four cluster solutions comparing data from different empirical sources.

A particular angle we put to the fore is the comparison of media in Europe using cultural values research. This angle of research has not been adopted widely but research suggests this method can be adopted fruitfully (Obijiofor \& Hanusch, 2011, p. 57). Western journalism (Deuze, 2005) is guided by an age-old occupational ideology that includes values as truth and accuracy, independence, fairness and impartiality, humanity and accountability (Ethical Journalism Network, $n / d$ ). This ideology influences journalism across the world, although different interpretations of journalism emerge on a global scale, as international research in the "Worlds of Journalism" initiative clearly proves (Hanitzsch \& Vos, 2018).

Another seminal work on comparative media systems, "Comparing Media Systems" by Hallin and Mancini (2004) identifies three models of media and politics, i.e., the liberal model, the democratic-corporatist model and the polarized pluralist model. These models appear in different regions of the western world, with Anglophone countries prevailing in the first model, continental European countries in the second model and SouthernEuropean countries in the third category. Notwithstanding the differences between the models, Hallin and Mancini (2004) identify an underlying trend of dedifferentiation. The largest differentiation between media and politics occurs within the liberal model. Precisely this model is gaining influence, shifting journalism towards a detached position, focused on reporting reality rather than wanting to change it.

Yet current journalists find themselves in a twisted position. On the one hand, journalism is analyzed as evolving towards detachment, as propagated by the liberal model in the typology by Hallin and Mancini (2004). On the other hand, journalists operate in an increasingly multicultural environment and some journalists see it as their duty to promote tolerance and cultural diversity, while others associate diversity with an unwanted degree of political correctness (Müller \& Frissen, 2014; Vandenberghe, d'Haenens, \& Van Gorp, 2014). Research among journalists in six European countries (Bennett, ter Wal, Lipinski, Fabiszak, \& Krzyzanowski, 2013, p. 261) 
proves this ambiguity, because systematic standards about diversity remain absent:

From the interviews it emerged that media professionals operate in an environment, either because of their own awareness, position in the political debate or their audience/readership profiles, where political correctness is either supported or shunned, resulting in different thresholds for what is seen as acceptable in terms of terminology and the definition of news.

The twisted position journalists have to face might also be influenced by the political climate journalists are living in. Research shows that across Europe (Callens, 2015) countries with a lenient policy towards immigration are also characterized by a tolerant public opinion climate. Recent migration policies in Germany for instance seem to confirm that a positive political discourse tends to foster a more accommodating media coverage: for instance "'solidarity', 'responsibility' and a welcoming culture are central themes in the German response to the crisis, especially in the German-language press" (Holmes \& Castaneda, 2016, p. 8).

Hence, the key question that emerges is the degree to which journalists also support tolerance and cultural diversity if particular societies and policies support tolerance and cultural diversity. Answering this key question is the aim of this article, by adopting a comparative approach through the integration of data from different sources that have not yet been connected in a multifocal intercultural comparative analysis up till now.

We studied the relationship between the media and other spheres based on data from the WJS international research study. These data contain information about the way journalists in 67 countries around the world view their professional roles. The empirical goal of this chapter is to compare the degree to which emancipative values in the WVS coexist with MIPEX policies (as reflected in prior research results) as well with journalistic role perceptions (a less explored domain so far). Our analysis will focus on countries for which data on the three research dimensions under study are available: the MIPEX policy index, the international WVS and the WJS international journalists study, resulting in a set of 24 countries.

\section{The Three Databases}

MIPEX shows an integrated score on eight policy areas in 40 western countries (MIPEX, n/d). The eight domains are labour market mobility, family reunion, education (since 2010), political participation, long-term residence, health, access to nationality, and anti-discrimination. An integrated score is calculated based on assessments of experts involved in a peer-review process. Although theoretically each domain has independent index scores (from 1 to 100), we refer to the integrated score, leading to an overall score out of 100 . The experts who score the different dimensions are independent legal scholars and practitioners within the domain of migration law (Niessen, 2009, p. 7). The consulted experts rely on indepth knowledge of the national legal and regulatory provisions on legal policy within their own country, and are also able to assess the regulatory frameworks of other countries from a comparative perspective. In order to achieve optimal objectivity in scoring, a second opinion of an extra expert is always requested to peer-review the scores of the individual expert assessments.

The MIPEX database is the only database used in this study that is derived from judgments by experts. The other two databases are based on survey research input. Current WVS data (WVS, 6th wave, 2010-2014) gathered in 60 countries made it possible to construct a set of different scales (World Values Survey, $n / d$ ). The WVS targets a representative adult population sample (at least 1,200 respondents per country) in different countries with the same survey questionnaire, aimed at providing essential insights into political and socialcultural change.

Especially relevant for research on immigration opinions is the Emancipative Values Index. Emancipative values emphasize freedom for everyone. Based on these values a scale is constituted ranging from 0 to 1 . The Emancipative Values Index is based on four sub-indices: autonomy, equality, choice and voice. The institutional spheres from which these four indices are derived are widely different. Autonomy mainly points at the autonomy of children in the family context. Equality refers to gender equality whereas choice is an indicator of ethical matters such as homosexuality, abortion and divorce. The last index, voice, refers to political participation. Previous research has shown that these core values (Welzer, 2013) are related with important concepts such as wellbeing, democracy and environmental sustainability. Our study thus wants to advance the scientific knowledge of the interrelational connections between values in policy (MIPEX), public opinion (WVS), and journalism (WJS).

The third database integrated in this intercultural media study consists of journalism variables. Journalism (Deuze, 2005) is, among other professions, known to have an ideology of its own, this ideology has been interpreted in many different ways across the globe. The WJS brought together researchers from 67 countries. In an unprecedented collaborative effort, more than 27,500 journalists were interviewed between 2012 and 2016, based on a common methodological framework (Worlds of Journalism, 2017). The WJS questionnaire deals with many dimensions of the occupational ideology. One of the questions raised was the degree to which journalists see it is as their professional role to promote tolerance and cultural diversity in the countries where they work, although this conception conflicts somewhat with the universal ideal of 'objectivity' (e.g., Broersma, 2015), which implies that journalists should not take sides in public debates, not even when ideals such as cultural diversity are at stake. Since immigration issues policy and public opinion are interrelated (Callens, 2015), we 
will study whether journalistic culture has been following this trend.

The question about journalistic roles relates to a wider set of questions regarding journalists' perceptions of professional roles (Worlds of Journalism Study, n/d). The items under question will be grouped under four headings: the monitoring role, the interventionist role, the collaborative role, and finally, the accommodative role of journalism. The monitoring role implies that journalists want to provide political information, monitor and scrutinize political and business actors, and motivate people to participate in politics. The interventionist role refers to journalists' advocating for social change, influencing public opinion, setting the political agenda and supporting national development. The collaborative role of journalism concentrates on supporting government policy and conveying a positive image of political leadership. Finally, the accommodative role of journalism refers to the provision of entertainment, news that attracts the largest audience as possible, and offers advice for daily life. In our study, we will investigate how the role promoting tolerance and cultural diversity relates to the other perceived roles.

Obviously, this analysis cannot answer questions on causality. It is most likely that journalism, cultural values and policy will influence each other in a constant intermingling of causes and effects. Each one of these databases has had a large influence on research, so that it is interesting to test whether their items correlate, although the databases are based on different theoretical frameworks. A large-scale multi-country study of values, policy and journalism measured with a unified theoretical background is lacking, and is practically unfeasible. Therefore, it is most necessary to compare these existing databases with different backgrounds to get a clearer idea of how culture, policy and journalism are intertwined.

\section{Hypotheses and Research Questions}

The links between MIPEX and public opinion (as expressed in the WVS) have been explored in earlier research. However, the links with journalism culture have not been extensively investigated yet. Nevertheless, it is logically consistent to assume that the degree to which journalists see it as their professional role to promote tolerance and cultural diversity is connected with integration-friendly options in policy and public opinion. This leads to the following hypotheses:
H1: In countries with high MIPEX values, journalists will view promoting tolerance and cultural diversity as an important professional role.

$\mathrm{H} 2$ : In countries with high emancipative values, journalists will view promoting tolerance and cultural diversity as an important professional role.

Furthermore, logical assumptions on the resonance between policy, public opinion dimensions and other dimensions of journalism culture are less derivable from earlier research. Therefore, we formulated open research questions here rather than hypotheses.

RQ1: Is there a correlation between (a) MIPEX and the role perception on promoting tolerance and cultural diversity and the four other journalistic role perceptions (i.e. monitoring, interventionist, collaborative, accommodative roles), and (b) emancipative values and the role perception on promoting tolerance and cultural diversity and the four other journalistic role perceptions?

RQ2: Are the different role perceptions of journalists correlated among each other?

To test these research questions, a database of countries was compiled that consisted of the data of 24 countries (see Table 1) that were included in all three central databases. The countries for which data are available are all Western countries, except for South Korea, the only non-Western country that met the criteria for inclusion in this study.

In addition to the study of the interrelations, we aimed to examine whether these countries group together on the dimensions specified in these three databases. Focusing specifically on the role perception that journalists would like to promote tolerance and cultural diversity, we ran analyses of the clustering of countries on three dimensions, combining each dimension with this particular role perception. These three dimensions are the MIPEX data, the WVS and the four other role perceptions borrowed from the WJS.

RQ3: How do Western countries cluster together when it comes to the role perception that journalists should promote tolerance and cultural diversity in correlation with data on integration policy, emancipative values and other journalistic role perceptions?

Table 1. Countries under study.

\begin{tabular}{llll}
\hline Australia & Estonia & Ireland & Spain \\
Austria & Finland & Latvia & Sweden \\
Belgium & Germany & The Netherlands & Switzerland \\
Bulgaria & Greece & Portugal & Turkey \\
Canada & Hungary & Romania & UK \\
Czech Republic & Iceland & South Korea & USA \\
\hline
\end{tabular}




\section{Methods}

\subsection{Method 1: Correlation Analysis}

We used a data set of 24 countries that met the abovementioned inclusion criteria. Each country was entered as a case, and each dimension from the chosen databases was entered as a variable. The scores have a value between 0 and 100 for each country on each dimension. These values are percentage scores in the case of the WVS, and the WJS, and Evaluation by Experts scores in the case of MIPEX. The constructed dataset is available upon request by the authors of this study. Pearson's correlations were calculated. Tables are presented with the dimensions from the four used databases on the horizontal and the vertical axis, indicating their interrelations. The cells of the tables are Pearson's correlation coefficients, representing the degree to which the different dimensions are intertwined. We calculated significance at the $.01, .05$ and .10 levels. The higher (.10) level of significance is included because we are dealing with a statistically small sample of mainly European countries $(N=24)$.

\subsection{Method 2: Cluster Analysis}

We ran a cluster analysis with four clusters to identify countries with similar or dissimilar profiles, while focusing on the role of journalism to promote tolerance and cultural diversity and combining each of the three databases with this role perception. We went through several exercises in dividing the map of Europe (plus some non-European countries) to come up with "four clusters of the press" when it comes to promoting tolerance and diversity, paraphrasing the seminal work of Siebert et al. (1956) on media models across the globe.

This allowed us to didactically evaluate the impact of each database on the specific role perception we focused on. The clustering method used is the furthest neighbor method, which tends to produce compact clusters of similar size. This method allows us to explain differences and similarities between groups of countries more didactically, compared to other methods that create a large center cluster and a few smaller clusters containing a few countries or containing only one. Graphically the clusters are presented using dendrograms, i.e., tree- like structures to visually present how countries group together and using maps of Europe, developed using the tool of Phil Archer (2013).

\section{Results}

\subsection{Correlation Analysis}

Emphasis (see Table 2) on the importance to promote tolerance does not significantly correlate with the MIPEX scores $(r=-0.133, p=.534)$, nor does this role perception significantly correlate with emancipative values ( $r=-0.331, p=.114)$. In other words, the hypotheses on MIPEX (H1) and emancipative values $(\mathrm{H} 2)$ are not confirmed.

Additional research questions deal with the link between MIPEX and emancipative values on the one hand, and other role perceptions of journalists on the other hand.

The journalistic role perceptions that correlate most strongly with the other databases are interventionism and collaboration. Both these journalistic role perceptions tend to be associated with lower MIPEX values (as asked in Research Question 1a) and lower emancipative values (as asked in Research Question 1b). The correlations are more blatant in the case of interventionism (i.e. MIPEX: $r=-0.479, p=.018$; emancipative values, $r=-0.714, p=.000)$. The correlations with collaboration, while somewhat lower, follow the same trend (i.e. MIPEX: $r=-0.402, p=.052$; emancipative values, $r=-0.590, p=.002)$. A correlation $(r=-0.355$, $p=0.088$ ) is also observed between less accomodative journalism cultures and higher MIPEX values.

Probing further on Research Question 2, the perception that journalists should promote tolerance and cultural diversity throughout their work co-occurs with the perception that they should monitor society $(r=0.538$, $p=.007)$ as well as with interventionism ( $r=0.691$, $p=.000$ ) (see Table 3). Interventionism itself is tied up with collaboration in a high correlation $(r=0.752$, $p=.000)$. A last couple of significant correlations to be noted in table 3 indicates that monitoring and accommodating forms of journalism clearly do not go together as indicated by a strong negative correlation $(r=-0.532$, $p=.007)$.

Table 2. Correlations between journalistic role perceptions and MIPEX and emancipative values.

\begin{tabular}{lll}
\hline & MIPEX & Emancipative values \\
\hline Tolerance & -0.133 & -0.331 \\
Monitoring & 0.217 & -0.126 \\
Interventionism & $-0.479^{* *}$ & $-0.714^{* * *}$ \\
Collaboration & $-0.402^{*}$ & $-0.590^{* *}$ \\
Accommodation & $-0.355^{*}$ & -0.034 \\
\hline
\end{tabular}

Note: ${ }^{*}=p<.1,{ }^{* *}=p<.05, * * *=p<.01$. 


\section{COGITATIO}

Table 3. Intercorrelations among journalistic role perceptions.

\begin{tabular}{|c|c|c|c|c|}
\hline & Monitoring & Interventionism & Collaboration & Accommodation \\
\hline Tolerance & $0.538 * * *$ & $.691 * * *$ & 0.305 & -0.009 \\
\hline Monitoring & & $0.367^{*}$ & 0.260 & $-0.532 * * *$ \\
\hline Interventionism & & & $0.752 * * *$ & 0.073 \\
\hline Collaboration & & & & 0.161 \\
\hline
\end{tabular}

Note: ${ }^{*}=p<.1,{ }^{* *}=p<.05,{ }^{* * *}=p<.01$.

\subsection{Cluster Analysis}

Only two countries have both a strong integration policy (high MIPEX) and a strong emphasis on tolerance among journalists (cf. Figure 1 and Figure 2) These two countries are Portugal and Sweden. Another small cluster consists of Latvia and Turkey: both on the outside of Europe, these two countries exhibit strong emphasis on

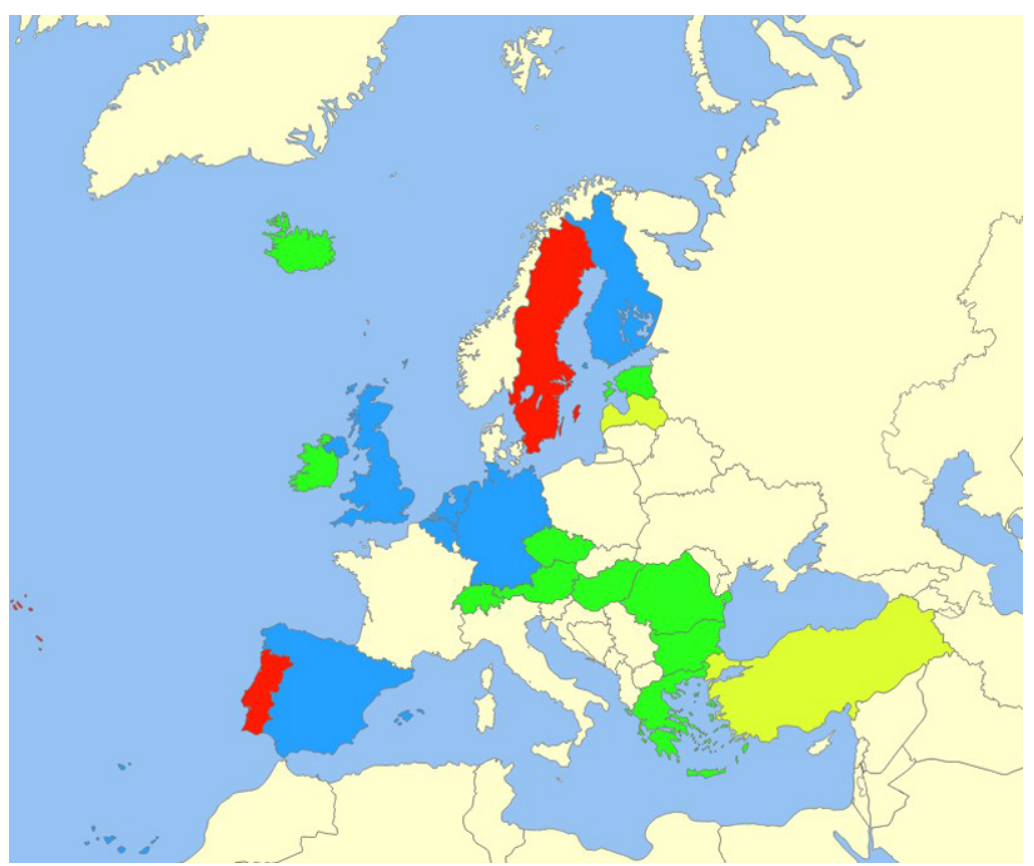

Figure 1. Four clusters of the press based on MIPEX and journalists' perception of their role as promoting tolerance and cultural diversity.

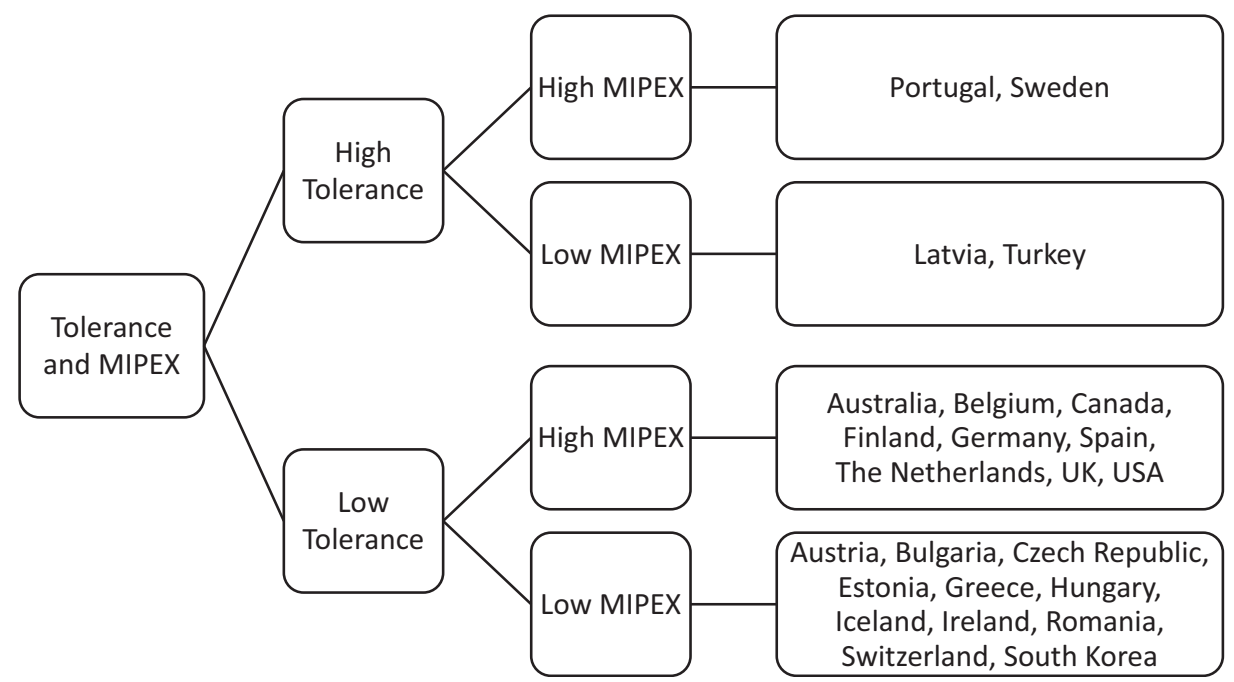

Figure 2. Four clusters of the press based on MIPEX and the role perception that journalists should promote tolerance and cultural diversity. 
tolerance among journalists, but also a weak integration policy, based on the MIPEX score.

Next to these two small clusters, we identified two larger clusters, which are clearly different regions. The first one consists of Western European countries. These countries have highly developed integration policies, but their journalists do not seem too concerned with promoting tolerance and cultural diversity. Next to the Western European countries, English-speaking Western countries outside Europe join this cluster: Australia, Canada and the United States.
The second large cluster includes only one Englishspeaking country: Ireland. Iceland is also included in this cluster. In addition to Iceland and Ireland, a large group of Central and Eastern European countries are part of the cluster as well. South Korea also joins this cluster.

The second clustering exercise is a further attempt to classify the data with four clusters using other variables. It resulted in four clusters of the press based on emancipative values measured in the WVS and the journalists' perception of their role as promoting tolerance and cultural diversity (Figure 3 and 4). This cluster solu-

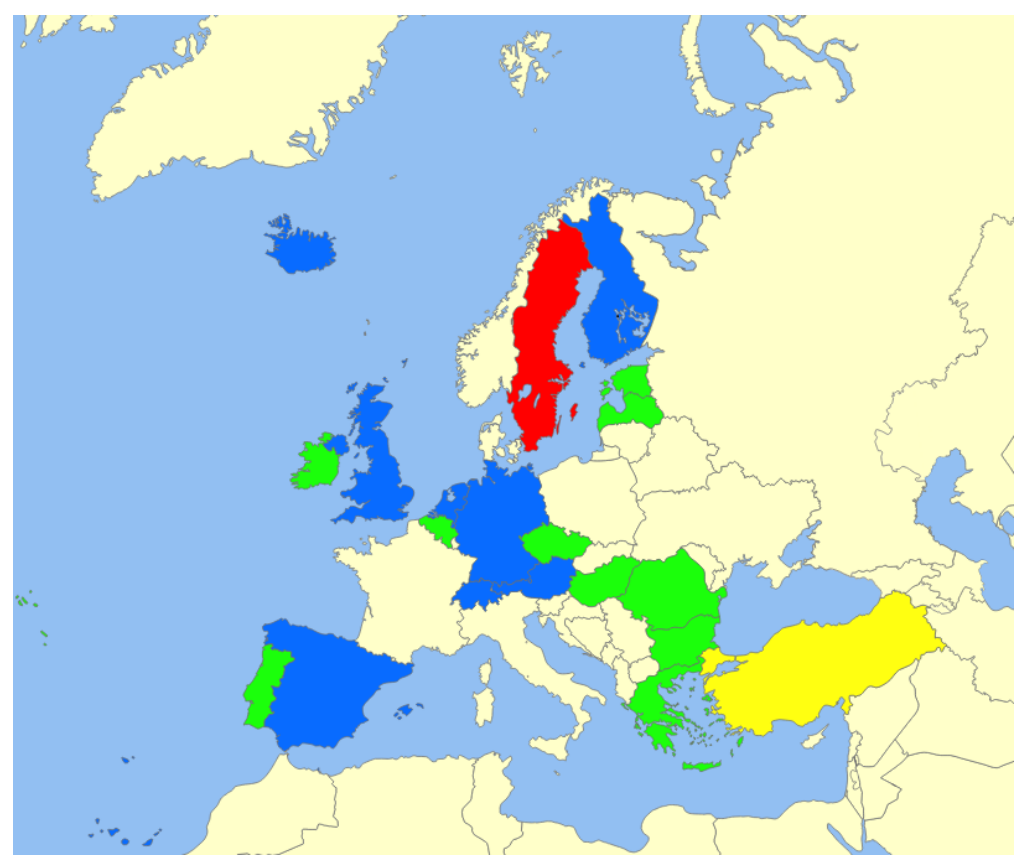

Figure 3. Four clusters of the press based on emancipative values and the journalists' perception of their role as promoting tolerance and cultural diversity.

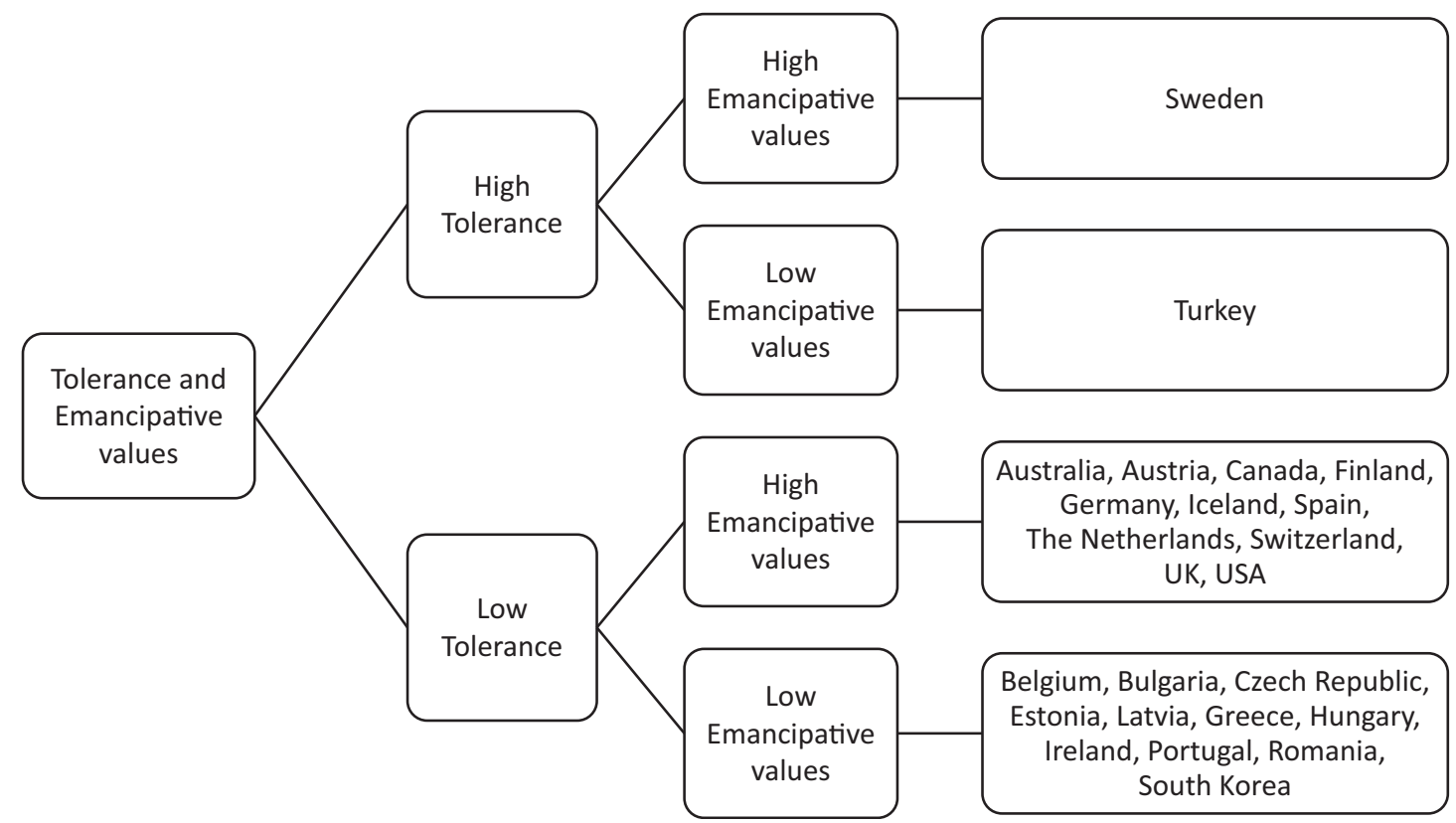

Figure 4. Four clusters of the press based on emancipative values and journalists' perception of their role as promoting tolerance and cultural diversity. 
tion also includes two small clusters and two large clusters. Two countries that already stood out in the first clustering exercise once again confirm their uniqueness. Sweden, high on MIPEX, is also scoring very high on the emancipative values. On the other hand, Turkey is scoring low on emancipative values as well as on MIPEX. Although the clustering method we used does not tend to form small clusters the uniqueness of Sweden and Turkey makes them one country cluster anyhow.

The two other countries-Portugal and Latvia-that belong to the first cluster's small groups join another, larger cluster. This cluster includes the bulk of countries that were grouped together in the 'low MIPEX-low tolerance' cluster. There is once again similarity between the large group of countries in the 'high emancipative values and low tolerance' cluster and the 'high MIPEX-low tolerance' cluster.

Finally, we produced clusters using interventionism and the journalistic focus on tolerance as input (Figure 5 and Figure 6). Iceland, a country appearing together with very different countries in the earlier cluster analyses, has its very own place in this cluster analysis, characterized by low interventionism and a low focus on promoting tolerance among journalists.

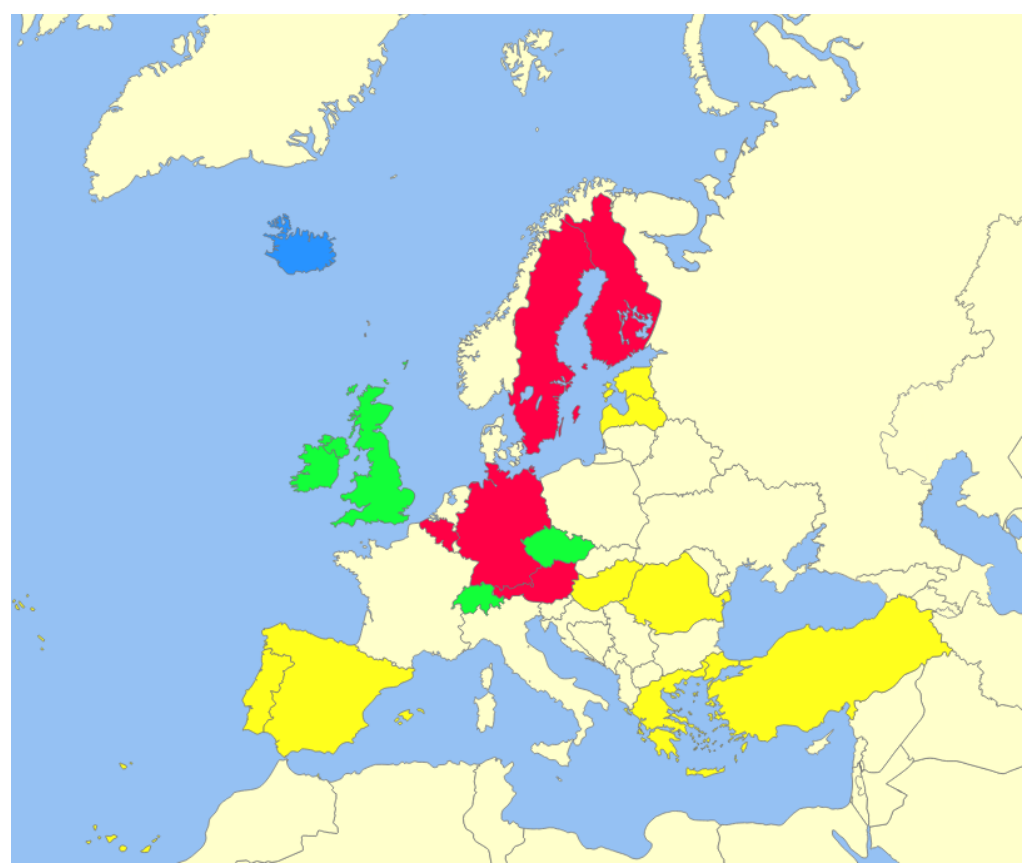

Figure 5. Four clusters of the press based on interventionism and the journalists' perception of their role as promoting tolerance and cultural diversity.

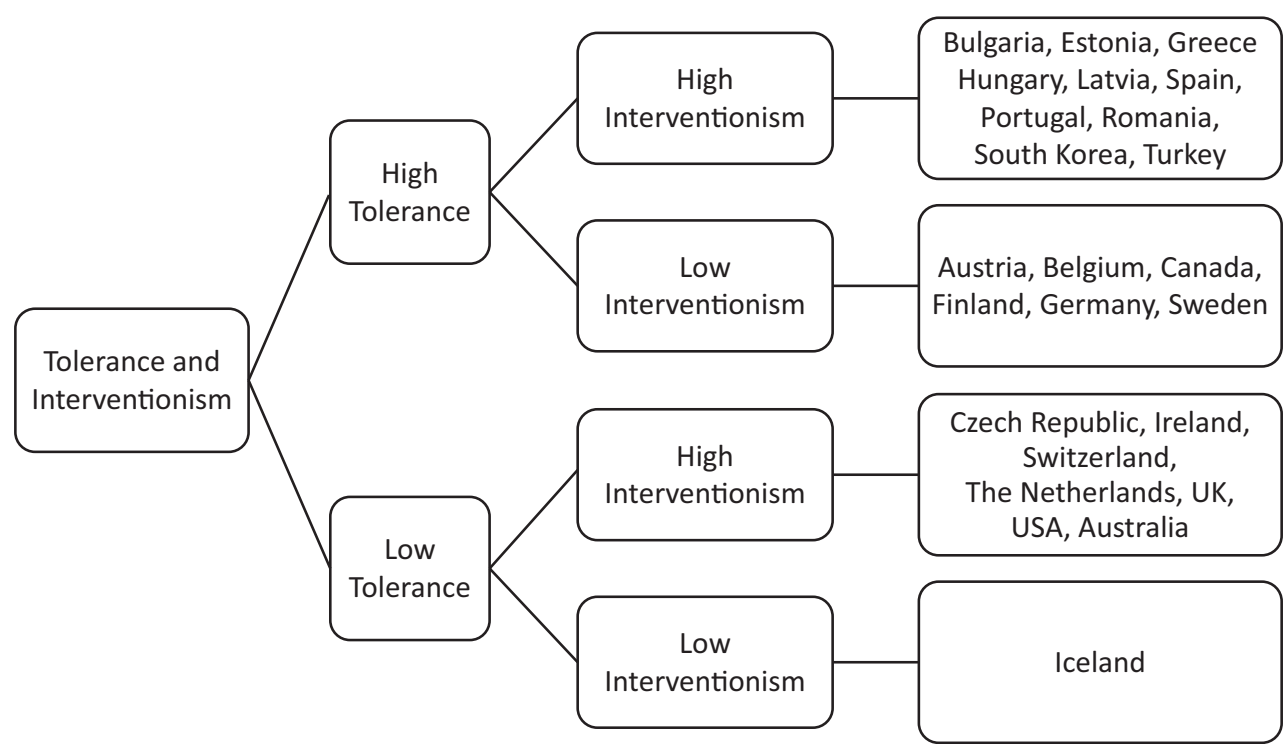

Figure 6. Four clusters of the press based on interventionism and journalists' perception of their role as promoting tolerance and cultural diversity. 
The combination of high interventionism with a high focus on tolerance among journalists has a clear regional Southern identity in this cluster analysis. Journalism in the Baltic countries has the features found in Southern countries specifically regarding the focus on tolerance and interventionism, making these countries also a part of this cluster.

In this cluster analysis the countries that are in the 'high-high' and 'low-low' clusters are easily identified from a geographic point of view. In the 'high-low' and 'low-high' groups, however, we find all the Germanic language-speaking countries, as well as Finland and the Czech Republic, two countries that are geographically close to these Germanic countries. It is however difficult to make a clear distinction between the two groups since the countries mentioned are scattered throughout these two clusters.

\section{Conclusion}

Our main conclusion is that, contrary to what we expected, countries with a higher focus on promoting tolerance in journalism cultures have less emancipative values and migrant-friendly policies (hence falsifying hypothesis 1 and 2). Promoting tolerance is a value in countries where journalistic culture is interventionist, and hence opposed to the values in policy (as measured by MIPEX, cf. RQ 1) and society (as measured by the WVS, cf. RQ 2). Our results indicate that journalism professionals in countries without a clear migrant integration policy seem to consider it as their explicit task to counterbalance the main policy line set out in their home country when it comes to immigration and openness.

Interventionism-often seen through its political dimension-can also be viewed as a will to actively promote some civic values among the public opinion. This refers to the 'opinion guide' role that journalists take on when political or social issues are being strongly debated. During the 2015 migration crisis certain media outlets adopted a welcoming tone towards refugees and tried to counter negative perceptions and stereotypes. Recent research shows that this is far from clear: The UNHCR report on press coverage of the refugee crisis in Europe shows that in many countries refugees have been presented in a negative light, primarily as a problem, and not as a resource that could benefit the receiving country (Berry, Garcia-Blanco, \& Moore, 2016; Finnish Institute, 2016).

International comparative research on interventionism (Hanitzsch et al., 2011) shows that this role conception of journalism tends to be unpopular in Western countries. The active promotion of particular values, ideas, groups and social change is generally not a characteristic of western journalistic cultures. This analysis shows that within a sample of mainly western countries differences appear, whereby in countries with less developed integration policies and emancipative values stronger interventionism in journalism is seen. Notwithstanding the importance of detachment in Western jour- nalism. Despite the unpopularity of detachment in Western journalism, journalists might also be under pressure to give opinions. In an era where journalism needs to adjust its profile to come up with something new next to the stream of Internet news data, giving opinions might be a fruitful business model, that replaces the classical ideal of detachment. Reunanen and Koljonen (2018) found that at least in one Western country, i.e., Finland, younger journalists adhere to alternative journalism ideals, that support journalists to give their opinions rather than offering merely a mirror of reality. This new tendency in journalism might actually counterbalance the evolution towards increased detachment as predicted by Hallin and Mancini (2004).

Moving on to the results of our cluster analyses (RQ 3), Sweden-one of the most welcoming countries during the recent so-called refugee crisis-typifies countries with both a tolerance-oriented journalism culture and strongly tolerance-oriented policies and public opinion. Nevertheless, Sweden has a journalistic workforce that does not adhere to interventionist ideals.

Our exercise identified different clusters of Southern countries, always including Turkey. Promoting tolerance in these countries is an important journalistic value, and this echoes interventionism in journalism culture, so as to remedy the lack of a tolerance-oriented policy and public opinion.

Clusters including other Northern and Southern countries are less straightforward. Eastern Europe occasionally joins the Southern cluster, but it also stands out of the latter because it has a lower focus on promoting tolerance and cultural diversity in journalism.

Some Western European countries join the cluster which includes Sweden, but not always. They are characterized by a non-interventionist journalism culture and adhere to migrant-friendly values (emancipative values index and MIPEX). However, promoting tolerance and cultural diversity is less important in their journalistic culture.

The Iberian countries Spain and Portugal are special in that they share similarities with Western European countries, especially in developing migrant-friendly policies, but they are also more interventionist in their journalism cultures.

These results raise the question of the specific values and discourses shared by journalism as a distinct field in societies. We see that journalists often claim to defend and promote tolerance and diversity, even in countries where the data point at a weaker culture of tolerance. Cultural and political causes of this particular discourse warrant further study. We must keep in mind that journalists' discourses ought to be considered in their normative dimension, which has long been developed by journalists themselves and still remains a place of debate and contestation in and outside the field. Discourses about core values of journalists often embrace broad notions such as freedom of speech, respect and tolerance. They are well developed in journalistic cultures and play an identity role that anchor journalism's autonomy in soci- 
ety (Hanitzsch \& Vos, 2018), even if those values and roles are not followed in day-to-day practices. The promotion of tolerance and diversity-just like other traditional values that underscore the links between western journalism and democratic systems-is thus a complex issue that requires a distinction between its declarative dimension (seen in databases such as the WJS) and its concrete expression in news stories and editorial lines.

It could be relevant, indeed, to underline that other variables such as the editorial lines of media outlets, might have a strong influence on the nature of the media narrative about refugees, as well as a national political agenda, for instance in case of elections, which tends to exacerbate tensions and positions. Editorial lines and political agendas might give a much more fragmented view on how the normative values are expressed or not in the narratives and the daily practices of coverage.

\section{Conflict of Interests}

The authors declare no conflict of interests.

\section{References}

Archer, P. (2013). Interactive map of Europe. Retrieved from https://philarcher.org/diary/2013/euromap

Bennett, S., ter Wal, J., Lipinski, A., Fabiszak, M., \& Krzyzanowski, M. (2013). The representation of thirdcountry nationals in European news discourse: Journalistic perceptions and practices. Journalism Practice, 7(3), 248-265.

Berry, M., Garcia-Blanco, I., \& Moore, K. (2016). Press coverage of the refugee and migrant crisis in the EU: $A$ content analysis of five European countries. Geneva: United Nations High Commissioner for Refugees.

Broersma, M. (2015). Objectiviteit als professionele strategie. Nut en functie van een omstreden begrip. [Objectivity as a professional strategy. Utility and function of a contested concept]. In J. Bardoel \& H. Wijfjes (Eds.), Journalistieke Cultuur in Nederland [Journalism Culture in the Netherlands] (pp. 163-182). Amsterdam: Amsterdam University Press.

Callens, M. (2015). Integration policies and public opinion: In conflict or in harmony? (LISER Working Paper no 2). Luxemburg: Institute of Socio-Economic Research. Retrieved from http://www.mipex.eu/sites/ default/files/downloads/files/mipexpublicopinionin conflictorinharmony.pdf

Deuze, M. (2005). What is journalism? Professional identity and ideology of journalists reconsidered. Journalism Theory Practice \& Criticism, 6(4), 443-465.

Ethical Journalism Network. (n/d). Retrieved from http://www.ethicaljournalismnetwork.org

Finnish Institute. (2016). Refugees and asylum seekers in press coverage. A comparative content analysis of texts published in Helsingin Sanomat and Aamulehti (FI), The Guardian and The Times (UK) and Le Soir and De Morgen (BE) newspapers in the time period from
1 January to 31 January 2016. London: The Finnish Institute.

Hallin, D. C., Mancini, P. (2004). Comparing media systems. Three models of media and politics. Cambridge: Cambridge University Press.

Hanitzsch, T. (2008). Comparative journalism studies. In K. Wahl-Jorgensen \& T. Hanitzsch (Eds.), The handbook of journalism studies (pp. 413-427). New York, NY: Routledge.

Hanitzsch, T., \& Altmeppen, K.-D. (2007). Über das Vergleichen: Komparative Forschung in deutschen kommunikationswissenschaftlichen Fachzeitschriften [On Camparing. Comparative research in German professional communication science journals] 1948-2005. Medien \& Kommunikationswissenschaft, 55(2), 185-203.

Hanitzsch, T., Hanusch, F., Mellado, C., Anikina, M., Berganza, R., Cangoz, I., . . . Wang Yuen, E. (2011). Mapping journalism cultures accross nations. Journalism Studies, 12(3), 273-293.

Hanitzsch, T., \& Vos, T. (2018). Journalism beyond democracy: A new look into journalistic roles in political and everyday life. Journalism, 19(2), 146-164.

Holmes, S. M., \& Castañeda, H. (2016). Representing the 'European refugee crisis' in Germany and beyond: Deservingness and difference, life and death. American Ethnologist, 43(1), 12-24.

Hooghe, M., \& De Vroome, T. (2015). How does the majority public react to multicultural policies? A comparative analysis of European countries. American Behavioral Scientist, 59(6), 747-768.

Leong, C. H., \& Ward, C. (2006). Cultural values and attitudes towards immigrants and multiculturalism: The case of the Eurobarometer survey on racism and xenophobia. International Journal of Intercultural Relations, 30, 799-810.

McCombs, M. (2011). The Agenda-setting role of the mass media in the shaping of public opinion (Unpublished Paper). Retrieved from https://www.research gate.net/publication/237394610_The_Agenda-Setting _Role_of_the_Mass_Media_in_the_Shaping_of_Pub lic_Opinion

MIPEX. (n/d). Retrieved from http://www.mipex.eu

Müller, F., \& Frissen, R. (2014). De diversiteitsparadox: Over de veranderende relatie tussen journalistiek en etnisch-culturele diversiteit. [The diversity paradox. On the changing relation between journalism and ethnic and cultural diversity]. Tijdschrift voor Communicatiewetenschap, 42(3), 265-285.

Niessen, J. (Ed.). (2009). Legal frameworks for the integration of third country nationals. Leiden: Martinus Nijhoff Publishers.

Obijiofor, L., \& Hanusch, F. (2011). Journalism across cultures: An introduction. Basingstoke: Palgrave MacMillan.

Puppis, M., \& d'Haenens, L. (2012). Comparing media policy and regulation. In F. Esser, \& T. Hanitzsch (Eds.), Handbook of comparative communication re- 
search (pp. 221-233). New York, NY: Routledge.

Reunanen, E., \& Koljonen, K. (2018). Not partisans, but participants. Journalism Studies, 19(5), 726-744.

Sarikakis, K. (2008). Communication and cultural policy research in Europe: A review of recent scholarship. In I. Fernández Alonso \& M. d. Moragas i Spà (Eds.), Communication and cultural policies in Europe (pp. 293-315). Barcelona: Generalitat de Catalunya.

Schroyens M., Meuleman B., \& Galle, J. (2015). Welcome to the club? Een comparatieve studie naar het verband tussen integratiebeleid en welvaartschauvinisme. [Welcome to the club. A comparative study on the link between integration policy and welfare chauvinism]. Mens en Maatschappij, 90(2), 117-142.

Siebert, F. S., Peterson, T., \& Schramm, W. (1956). Four theories of the press. Urbana, IL: University of Illinois Press.

Vandenberghe, H., d'Haenens, L., \& Van Gorp, B. (2014). Staat diversiteit op de journalistieke agenda? Verkennende analyse op basis van diepte-interviews met Vlaamse krantenjournalisten. [Is diversity on the journalistic agenda? Explorative analysis based on in-depth interviews with Flemish newspaper journalists] Nieuwsmonitor: Nieuwsbrief Steunpunt Media Steunpunt Media, 19. Retrieved from http://www.steunpuntmedia.be/?page_id=17
Valenzuela, S. (2011). Materialism, postmaterialism and agenda-setting effects: The values-issues consistency hypothesis. International Journal of Public Opinion Research, 23(4), 437-463.

Vliegenthart, R. (2015). Mediamacht. De interactie tussen media, publiek en politiek. [Media Power. The Interaction between media, audience and politics]. In J. Bardoel \& H. Wijfjes (Eds.), Journalistieke cultuur in Nederland [Journalism Culture in the Netherlands] (pp. 221-236). Amsterdam: Amsterdam University Press.

Watson, B. R., \& Riffe, D. (2013). Perceived threat, immigration policy support, and media coverage: Hostile media and presumed influence. International Journal of Public Opinion Research, 25(4), 459-479.

Walgrave, S., \& Van Aelst, P. (2016). Political agenda setting and the mass media. In W. R. Thompson (Ed.), Oxford research encyclopedia of politics (pp. 1-26). New York, NY: Oxford University Press. https:// doi.org/10.1093/ACREFORE/9780190228637.013.46

Welzel, C. (2013). Freedom rising human empowerment and the quest for emancipation. Cambridge: Cambridge University Press.

Worlds of Journalism Study. (n/d). Retrieved from http:// www.worldsofjournalism.org

World Values Survey. (n/d). Retrieved from http:// www.worldvaluessurvey.org

\section{About the Authors}
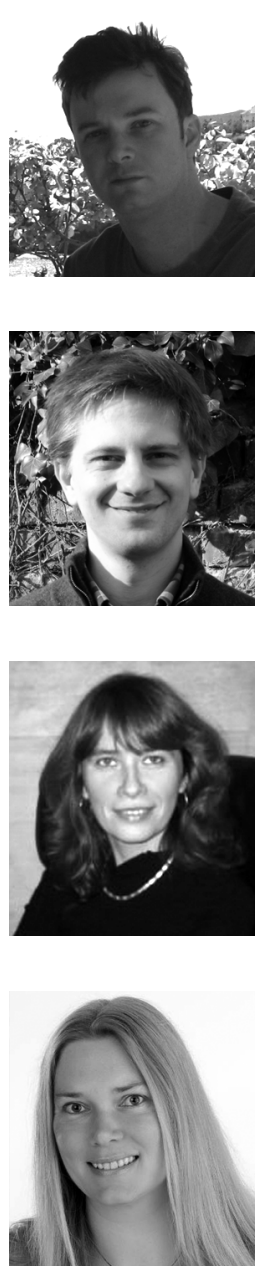

Stefan Mertens (PhD, Catholic University of Brussels, 2004) is a Postdoctoral Researcher in communication science at the University of Leuven. He is also partner for the Dutch speaking part of Belgium in the international Worlds of Journalism Project (http://www.worldsofjournalism.org). His research interests include quantitative and qualitative content analysis, media and diversity, media policy analysis, survey research, research on cultural values and journalism cultures and audience reception studies.

Olivier Standaert is an Assistant Professor at the Louvain School of Journalism (Université Catholique de Louvain, Belgium). His research and teaching focus on methodological issues in journalism studies, journalism cultures, professional identities, careers and labour markets of media workers. As a former freelance journalist, he previously worked for various Belgian newspapers and magazines. 